\title{
The Effects of Heating and Dilution On the Rheological and Physical Properties of Tank 241-SY-101 Waste
}

J. M. Tingey

P. R. Bredt

E. H. Shade

October 1994

Prepared for the U.S. Department of Energy under Contract DE-AC06-76RLO 1830

Pacific Northwest Laboratory Operated for the U.S. Department of Energy by Battelle Memorial Institute 


\title{
DISCLAIMER
}

This report was prepared as an account of work sponsored by an agency of the United States Government. Neither the United States Government nor any agency thereof, nor Battelle Memorial Institute, nor any of their employees, makes any warranty, expressed or implied, or assumes any legal liability or responsibility for the accuracy, completeness, or usefulness of any information, apparatus, product, or process disclosed, or represents that its use would not infringe privately owned rights. Reference herein to any specific commercial product, process, or service by trade name, trademark, manufacturer, or otherwise does not necessarily constitute or imply its endorsement, recommendation, or favoring by the United States Government or any agency thereof, or Battelle Memorial Institute. The views and opinions of authors expressed herein do not necessarily state or reflect those of the United States Government or any agency thereof.

\author{
PACIFIC NORTHWEST LABORATORY \\ operated by \\ BATTELLE MEMORIAL INSTITUTE \\ for the \\ UNITED STATES DEPARTMENT OF ENERGY \\ under Contract DE-ACO6-76RLO 1830
}

Printed in the United States of America

Available to DOE and DOE contractors from the

Office of Scientific and Technical Information, P.O. Box 62, Oak Ridge, TN 37831;

prices available from (615) 576-8401. FTS 626-8401.

Available to the public from the National Technical Information Service,

U.S. Department of Commerce, 5285 Port Royal Rd., Springfield, VA 22161. 
PNL-10198

UC-2030

\section{The Effects of Heating and Dilution On the Rheological and Physical Properties of Tank 241-SY-101 Waste}

J. M. Tingey

P. R. Bredt

E. H. Shade

November 1994

Prepared for

the U.S. Department of Energy

under Contract DE-AC06-76RLO 1830

Pacific Northwest Laboratory

Richland, Washington 99352 



\section{Executive Summary}

The effects of heating and dilution on the rheological and physical properties of a composite sample taken from the nonconvective slurry region of Hanford waste Tank 241-SY-101 were investigated. The composite sample was prepared by combining three samples from segments $16,16 R$, and 18 taken during the Window $\mathrm{C}$ event, core sample 22. Before preparation of the composite sample, the shear strength of each of these samples was determined and found to be much lower than the shear strength observed during previous characterization activities. This lower shear strength was probably observed because the original analyses were performed on unmixed samples, whereas the samples used for these dilution tests had been hand-stirred before shipment to Pacific Northwest Laboratory (PNL). ${ }^{\text {(a) }}$ The composite sample was divided into five samples. Four of the divided samples were diluted to 10,20 , 35 , and 50 volume percent $2 \underline{\mathrm{M} \mathrm{NaOH}}$, respectively; the dilutions were prepared by mixing the $\mathrm{NaOH}$

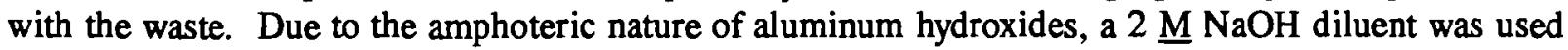
to avoid significantly decreasing or increasing the $\mathrm{pH}$ of the sample and precipitating dissolved salts.

Selected rheological and physical properties were determined on the one undiluted and the four diluted $(10,20,35$, and 50 volume percent $2 \underline{\mathrm{M} \mathrm{NaOH}}$ ) samples at three temperatures $(50,70$, and $90^{\circ} \mathrm{C}$ ). The analyses were performed on duplicate samples from each of the five dilution levels. Shear stress as a function of shear rate, yield stress, settling behavior, slurry density, filtered solids and filtrate densities, and weight percent filtered solids were the properties obtained.

The rheological properties (yield stress and shear stress as a function of shear rate) of samples from Tank 241-SY-101 are strongly dependent upon sample history. A decrease in the yield stress of the various samples was observed after the waste was subjected to mixing or shearing. This decrease in the yield stress appears to be irreversible, at least in a time span of two years. Because of this dependence upon the sample shear history, rheological studies should be performed on undisturbed samples if data on undisturbed in-tank properties are desired. Alternatively, in situ rheological measurements may be preferable.

The one undiluted and all four of the diluted samples exhibited sample history dependent yield pseudoplastic behavior. The yield stress of these samples decreases with increasing temperature and dilution. Most of the decrease in the yield stress is observed between 50 and $70^{\circ} \mathrm{C}$ and 0 and $10 \%$ $\mathrm{NaOH}$ dilutions.

The apparent viscosities of the one undiluted and the four diluted samples at shear rates higher than $150 \mathrm{~s}^{-1}$ are weakly dependent upon sample shear history. No significant changes in apparent viscosity were observed over multiple runs at the higher shear rates. The apparent viscosities of the four diluted and one undiluted sample are dependent upon both temperature and dilution, with the temperature dependence most evident in those samples with higher solids content.

(a) Pacific Northwest Laboratory is operated for the U.S. Department of Energy by Battelle Memorial Institute under Contract DE-AC06-76 RLO 1830. 
Only the 50 and $35 \% \mathrm{NaOH}$ dilutions exhibited any significant settling and therefore, could be vacuum filtered. Centrifugation filtering methods were used successfully to separate solids and liquids in the undiluted, 10 , and $20 \%$ diluted samples.

The densities of the solids and filtrate obtained from the vacuum and centrifugation filtration methods were independent of temperature. The filtered solids and filtrate densities were similar for all samples except the $50 \% 2 \underline{\mathrm{M} \mathrm{NaOH}}$ dilution.

The weight percent of solids in the slurries obtained by filtering is dependent upon dilution and temperature. The dependence of the weight percent solids on temperature increases as the amount of solids in the sample increases; therefore, only slight dependencies on temperature were observed in the higher volume percent dilutions. 


\section{Acknowledgments}

The authors would like to thank Jerry Johnson and Norton McDuffie of Westinghouse Hanford Company (WHC), and Joe Brothers of PNL for their comments. The authors are also grateful to Guillermo Terrones of PNL for his careful reading of and his contributions to the manuscript. 


\section{Contents}

Executive Summary $\ldots \ldots \ldots \ldots \ldots \ldots \ldots \ldots \ldots \ldots \ldots \ldots \ldots \ldots$ iii

Acknowledgments $\ldots \ldots \ldots \ldots \ldots \ldots \ldots \ldots \ldots \ldots \ldots \ldots \ldots \ldots \ldots$

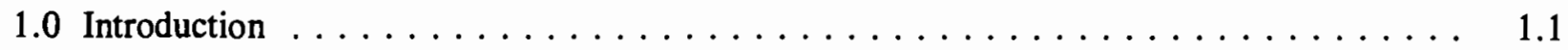

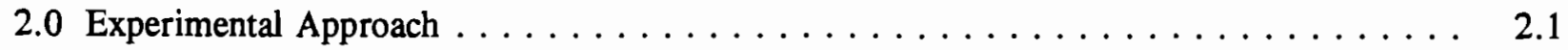

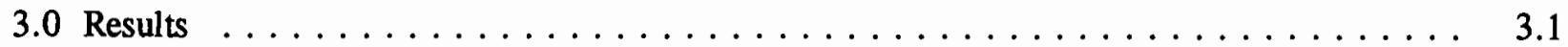

3.1 Rheological Properties $\ldots \ldots \ldots \ldots \ldots \ldots \ldots \ldots \ldots \ldots \ldots \ldots \ldots \ldots \ldots$

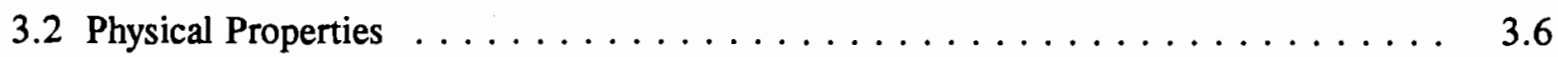

3.3 Result Uncertainties $\ldots \ldots \ldots \ldots \ldots \ldots \ldots \ldots \ldots$

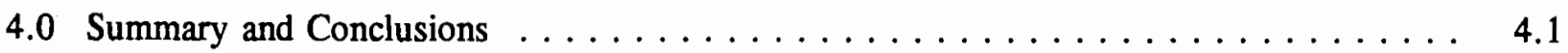

5.0 References $\ldots \ldots \ldots \ldots \ldots \ldots \ldots \ldots \ldots \ldots \ldots \ldots \ldots \ldots \ldots \ldots \ldots$ 


\section{Figures}

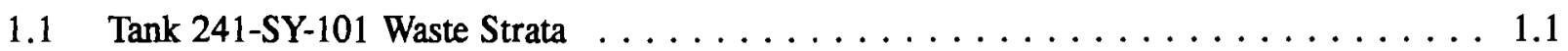

1.2 Tank 241 -SY-101 Risers Location (Top View) $\ldots \ldots \ldots \ldots \ldots \ldots \ldots \ldots \ldots$

2.1 Shear Strength Assemblies: a) Sample Container, b) Lid, c) Shear Vane,

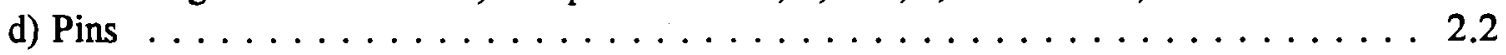

2.2 Typical Torque Versus Time Curve $\ldots \ldots \ldots \ldots \ldots \ldots \ldots \ldots \ldots \ldots .4$

3.1 Yield Point as a Function of Temperature and Volume Percent $\mathrm{NaOH} \ldots \ldots \ldots .3$

3.2 Apparent Viscosities at a shear rate of $400 \mathrm{~s}^{-1}$ of Undiluted and Four Diluted Samples as a Function of Temperature and Volume Percent $\mathrm{NaOH} \ldots \ldots \ldots \ldots .4$

3.3 Densities of Filtrate and Filtered Solids as a Function of Temperature and

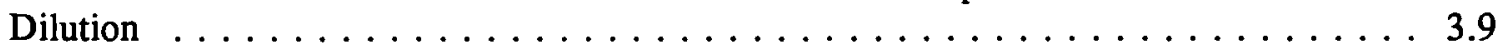

\section{Tables}

3.1 Shear Strength of Window C, Core Sample 22, Segment Samples $\ldots \ldots \ldots \ldots \ldots 3.1$

3.2 Yield Point Prior to Shearing $\ldots \ldots \ldots \ldots \ldots \ldots \ldots \ldots \ldots \ldots \ldots \ldots \ldots \ldots \ldots \ldots$

3.3 Apparent Viscosity at $50^{\circ} \mathrm{C}$ as a Function of Volume Percent $\mathrm{NaOH} \ldots \ldots \ldots \ldots 3.5$

3.4 Apparent Viscosity at $70^{\circ} \mathrm{C}$ as a Function of Volume Percent $\mathrm{NaOH} \ldots \ldots \ldots \ldots .5 .5$

3.5 Apparent Viscosity at $90^{\circ} \mathrm{C}$ as a Function of Volume Percent $\mathrm{NaOH} \ldots \ldots \ldots . .5$

3.6 Volume Percent Settled Solids $\ldots \ldots \ldots \ldots \ldots \ldots \ldots \ldots \ldots \ldots \ldots \ldots$

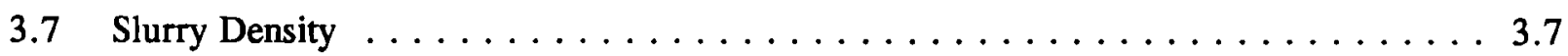

3.8 Settled Solids Density $\ldots \ldots \ldots \ldots \ldots \ldots \ldots \ldots \ldots \ldots \ldots \ldots \ldots \ldots \ldots \ldots$

3.9 Weight Percent Filtered Solids $\ldots \ldots \ldots \ldots \ldots \ldots \ldots \ldots \ldots \ldots \ldots \ldots \ldots \ldots$

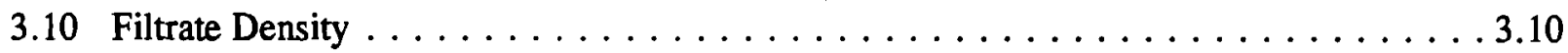

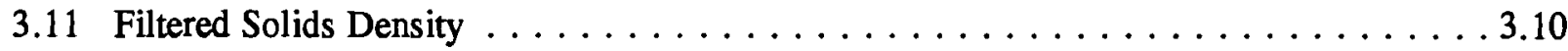


. 


\subsection{Introduction}

Of the 177 high-level waste underground storage tanks at the Hanford Site, 25 have been identified as being potentially capable of generating and releasing flammable gas (Leach and Stahl 1993; Hanlon 1994). Tank 241-SY-101 has exhibited periodic releases of gas, and in some cases the gas released has exceeded the lower flammable gas limit (Babad et al. 1991). The components of the released gas from Tank 241-SY-101 are hydrogen, nitrous oxide, nitrogen, ammonia, carbon monoxide, and methane (LANL 1994). A mitigation strategy that may effectively reduce the retention and release of these gases and the release of flammable gases is dilution coupled with heating of the tank wastes. The purpose of this work was to determine changes in rheological and physical properties caused by heating and dilution of actual 241-SY-101 waste.

Tank 241-SY-101 contains approximately 4.2 million liters of complexant concentrate (CC) and double-shell slurry (DSS) wastes. Three distinct strata have been observed in this tank, including a crust on the top of the tank (approximately $100 \mathrm{~cm}$ thick), a convective liquid (528 cm thick), and a nonconvective slurry ( $391 \mathrm{~cm}$ thick). The nonconvective slurry stratum was previously defined as two strata-the nonconvective slurry, and a heel approximately $50 \mathrm{~cm}$ thick at the bottom of the tank (Herting et al. 1992a; Reynolds 1992, 1993). A schematic of the strata in Tank 241-SY-101 and the core sample segments associated with these strata are shown in Figure 1.1.

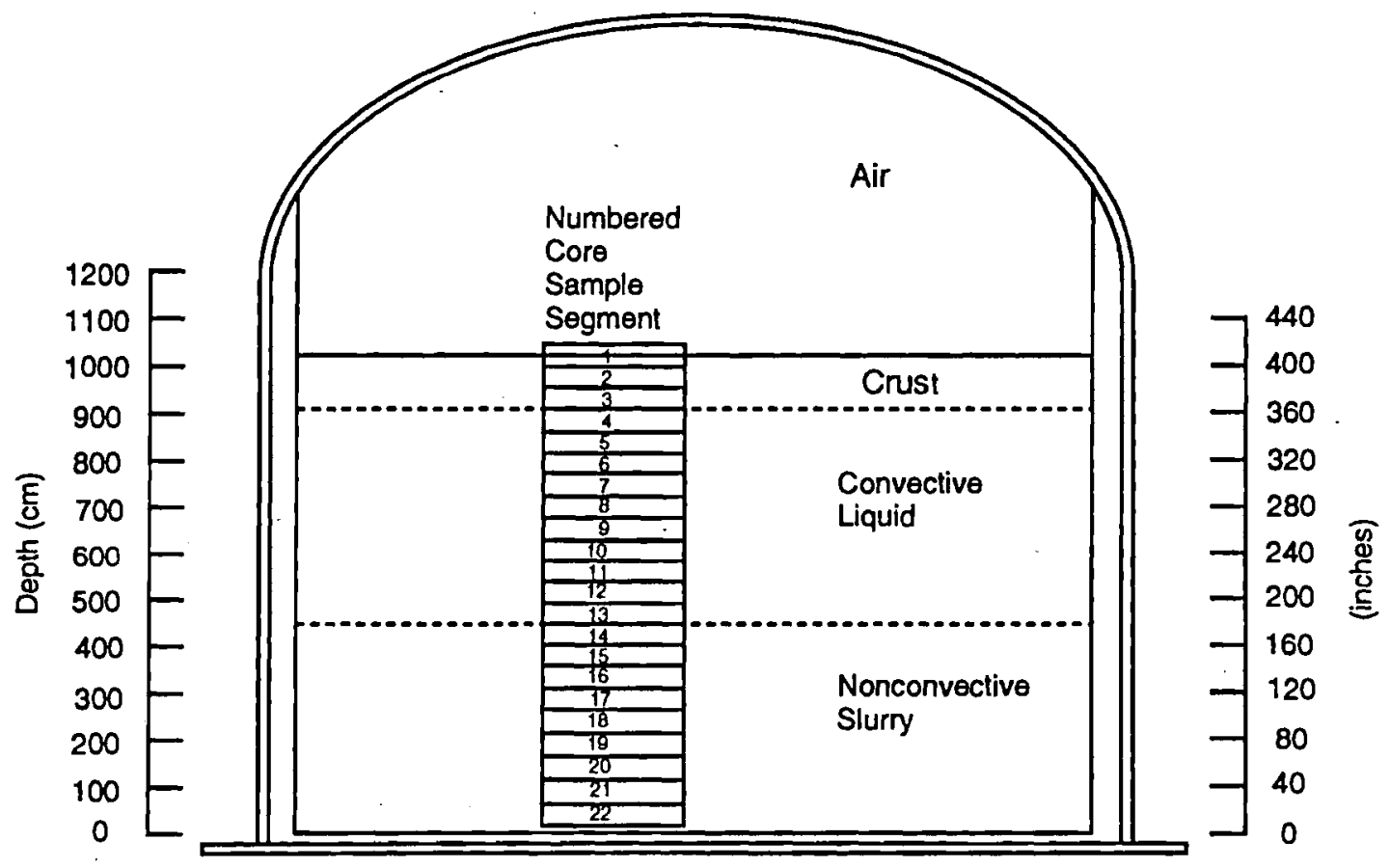

Figure 1.1. Tank 241-SY-101 Waste Strata 
In May and December 1991, following periodic gas releases, samples of the waste in Tank 241-SY-101 were obtained. The time periods following these gas releases, when it was considered safe to obtain samples from the tank, are called "Window C" (May 1991) and "Window E" (December 1991), respectively. Extensive chemical and physical characterizations were performed on the samples obtained during Windows C and E (Herting et al. 1992a, 1992b; Reynolds 1992, 1993).

Gas is generated within this tank because of the chemical and radiochemical nature of the waste. Before placement of a mixing pump in this tank, part of the generated gas was trapped in the nonconvective slurry layer. The gas is apparently retained as bubbles attached to the solids in the waste. The amount of gas trapped increases until buoyancy forces overcome the cohesive strength of the solids, with a resulting gas release and rise of the solids through the convective layer. This rise of the nonconvective slurry and release of trapped gases is called a "rollover."

In previous studies, the rheological and physical properties of samples taken from an auger sample from riser $22 \mathrm{~A}$ (see Figure 1.2 for location); portions of segments 4, 8, 13, 15, 19, and 22 from Window $C$ core sample 22 (these segments came from riser 22A); and segments 3, 8, 15, and 19 from Window E core sample 28 (these segments came from riser 11B) were determined in testing at the High-Level Radiochemistry Facility (HLRF) at Pacific Northwest Laboratory (PNL). The results from these characterization efforts are contained in three letter reports that were submitted to WHC. ${ }^{(a)}$

Current work quantified the effects of heating coupled with $\mathrm{NaOH}$ dilution of a combination of waste samples from Tank 241-SY-101 characteristic of a non-convective layer. A series of dilutions of a composite sample prepared from core samples taken from Tank 241-SY-101 during the Window C event was studied to assess the effects of dilution and heating on the volume, settling behavior, and rheological properties (yield stress and apparent viscosity) of the solids in that tank. The ability of the nonconvective slurry to retain gas bubbles is linked with the rheological and physical properties of the tank wastes; therefore, the effects of heating and dilution on the rheological and physical properties of samples from Tank 241-SY-101 were studied. The scope of this task did not include any activities to determine the chemical composition in the solids or supernatant liquid fractions of the diluted waste, the gas generation and release rates of the diluted waste, or the compositions of the gas released from the diluted waste.

(a) Tingey, J. M. February 1992. Physical Characterization of Tank 101-SY Core Samples from Window $C$. Letter report to Westinghouse Hanford Company. Pacific Northwest Laboratory, Richland, Washington.

Tingey, J. M. May 1992. Rheological Properties of Waste from Tank 101-SY. Letter report to Westinghouse Hanford Company. Pacific Northwest Laboratory, Richland, Washington. Tingey, J. M. June 1992. Physical Measurements of Waste from Tank 241-SY-101 Window E. Letter report to Westinghouse Hanford Company. Pacific Northwest Laboratory, Richland, Washington. 


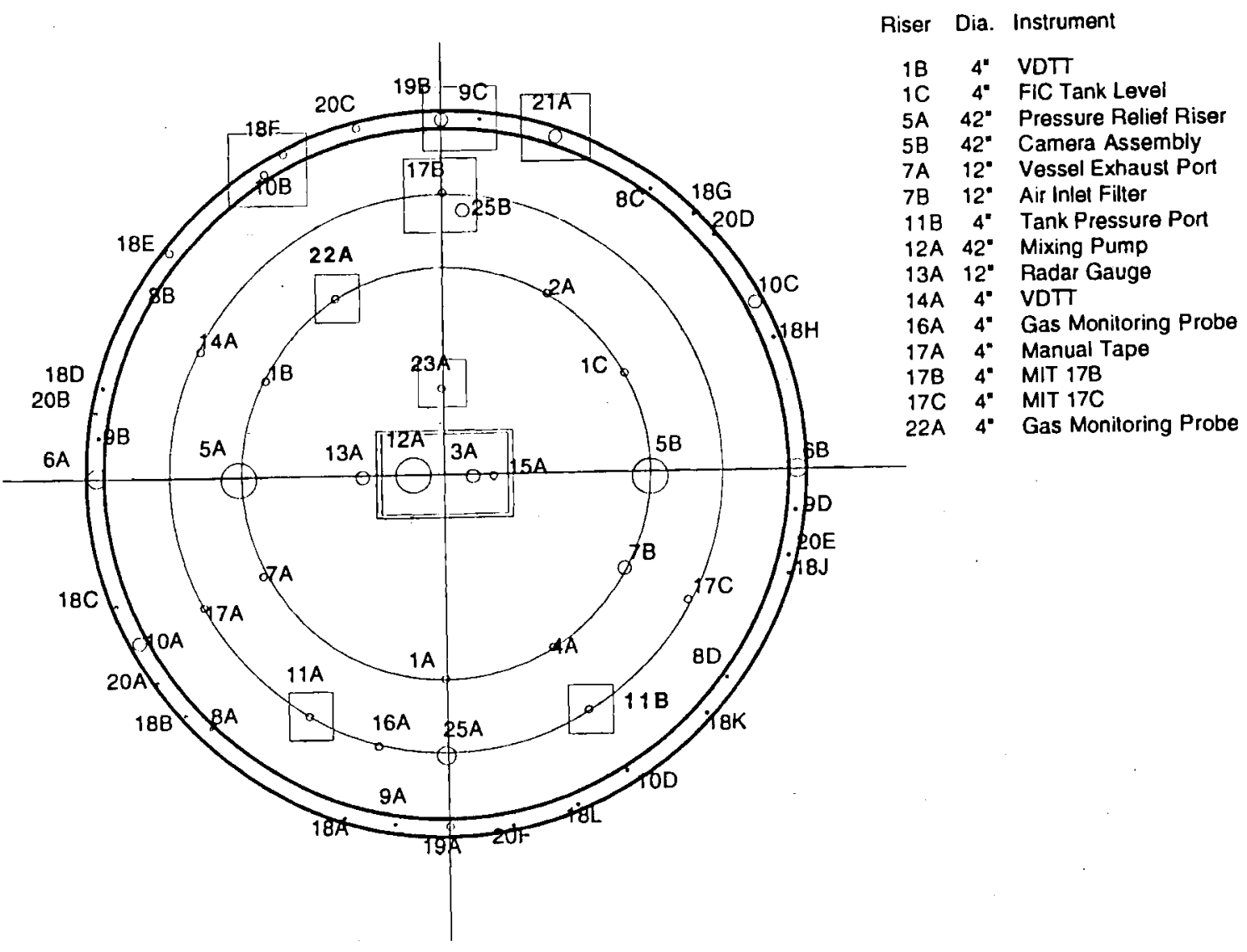

Figure 1.2. Tank 241-SY-101 Risers Location (Top View)

The experimental approach and results of this heating and dilution study on Tank 241-SY-101 waste samples are described in Sections 2 and 3, respectively. In Section 3.1, a discussion of the rheological properties of the waste as a function of shearing forces, volume percent dilution, and temperature is presented. In Section 3.2, the physical properties of the waste dilutions are described, including the densities of the slurry, filtered solids, and filtrate; the settling behavior; and the percent filtered solids in the composite sample and each of four composite dilutions. A brief discussion of the results and uncertainties is given is Section 3.3. The conclusions of this investigation are reported in Section 4. However, conclusions as to the viability of heating and dilution of 241-SY-101 waste contents as a permanent mitigation strategy are not within the scope of this document. Consideration of flammable gas mitigation strategies are addressed in Stewart et al. (1994). 


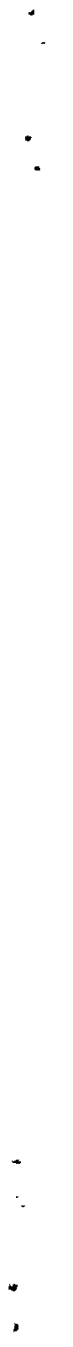




\subsection{Experimental Approach}

The data in this investigation were collected according to the "Laboratory Procedure for Measurement of Physical and Rheological Properties of Solutions, Slurries and Sludges" (PNL-ALO-501 section from PNL-MA-599 Vol. 6). To obtain accurate data to calculate solids density, some modifications to the standard PNL procedure were made, as explained below. The raw data can be found in Laboratory Notebooks BNW-54731 and BNW-55600. All experimental work was performed according to the "Good Practices Standards" (PNL-MA-70 Part 2).

Six samples from three segments of the core sample taken during the Window $C$ event, core sample 22, were delivered to the HLRF. A composite sample was prepared by combining the six duplicate samples from segments 16,16R, and 18 (see Figure 1.1). The individual samples received from WHC. were all placed in a single jar and stirred with a spatula for 10 minutes. The composite sample was divided into five smaller samples. Four of these samples were diluted to $10,20,35$, and 50 volume percent $2.0 \mathrm{M} \mathrm{NaOH}$ by mixing each subsample of known mass and density with the appropriate volume of diluent using the same approach as with the composite. For example, the 35 volume percent dilution was prepared by mixing $35 \% 2 \underline{\mathrm{M} \mathrm{NaOH}}$ and $65 \%$ composite sample. All of these dilutions were made on a volume basis. Due to the amphoteric nature of aluminum hydroxides, a $2 \underline{\mathrm{M} \mathrm{NaOH}}$ diluent was used to avoid significantly decreasing or increasing the $\mathrm{pH}$ of the sample and precipitating . dissolved salts. Density, volume and weight percent settled solids, yield stress, apparent viscosity, and weight percent filtered solids were determined for each sample. The densities of the settled and filtered solids and the filtrates were also determined.

Knowledge of the yield stress of a material is a key ingredient in the determination of a rheological equation of state used for modeling transport processes of viscoplastic materials such as the waste in Tank 241-SY-101. The yield stress is the shear stress above which a material flows readily. Below this value, the material behaves like a solid. In the present work, two methods were used to measure the yield stress of the samples-a rotating shear vane shown in Figure 2.1, and data extrapolation of the flow curves (shear stress plotted versus shear rate) to zero shear rate. To distinguish between the results obtained from both methods, the value of the yield stress obtained with the shear vane (direct method) will be referred to as "shear strength," whereas the yield stress obtained from extrapolation of the flow curves (indirect method) will be referred to as "yield point."

The apparent viscosity $\eta$, which is defined as the ratio of shear stress $\tau$ to shear rate $\gamma$, is another quantity used in the description of rheological properties of non-Newtonian materials.

$$
\eta(\gamma, \mathrm{t})=\frac{\tau(\mathrm{t})}{\gamma(\mathrm{t})}
$$




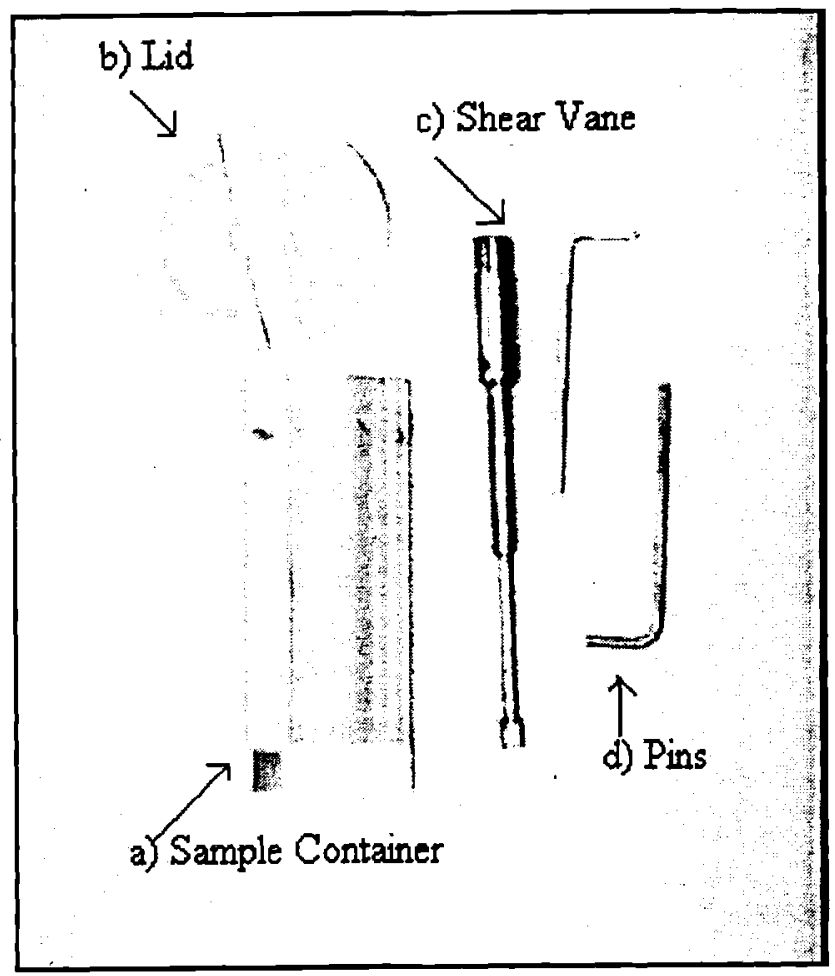

Figure 2.1. Shear Strength Assemblies: a) Sample Container, b) Lid, c) Shear Vane, d) Pins

Because the samples tested in this study exhibited time-dependent yield pseudoplastic behavior (thixotropy), the apparent viscosities are a function of the time duration of the test, the maximum shear rate $\gamma_{\max }$ attained by the viscometer, and whether the shear rate was increasing or decreasing. In a typical viscometric test, the shear rate can be represented by a function of time in the following form:

$$
\gamma=\left\{\begin{array}{cl}
f(t), & 0<t<\chi \\
f(2 \chi-t), & x<t<2 \chi
\end{array}\right.
$$

where the function $f(t)$ describes the manner in which the shear rate is increased $(0<t<\chi)$ or decreased $(\chi<t<2 \chi)$ and $\chi$ is the time at which $\gamma_{\max }$ was reached. In this study, the shear rate was continuously increased from 0 to $480 \mathrm{~s}^{-1}\left(\gamma_{\max }\right)$, then continuously decreased to $0 \mathrm{~s}^{-1}$.

The rheological measurements obtained in time intervals $[0, \chi]$ and $[\chi, 2 \chi]$ are called the "up-curve" and the "down-curve," respectively. In the absence of time-dependent effects on the rheology of the sample, both curves are identical. However, a discrepancy in the up-curve and down-curve suggests thixotropic behavior, as was observed in the undiluted and diluted samples. A quantitative determination of the thixotropic parameters is beyond the scope of this investigation.

Density is calculated by dividing the mass of the sample by the measured volume. The density of the composite was obtained by centrifuging a known mass of sample and measuring the volume of that centrifuged sample. Centrifuge filtration was performed at $1000 \mathrm{xg}$ for 15 minutes with AMICON 
CF25 Centriflo membrane cones. The densities of the dilutions were obtained by allowing a sample of known mass to settle in a $15 \mathrm{~mL}$ graduated centrifuge cone and measuring the total volume of the sample.

The settled sample used to measure the density was also used to determine the volume and weight percents of the settled solids and the amount of supernatant. If supernatant existed above the settled solids, the supernatant was pipetted from the centrifuge cone being careful not to disturb the settled solids. The volume and mass of supernatant was measured in a graduated cylinder of known mass. The volume and mass of the supernatant having been determined, the volume and mass of the solids were then calculated as the difference between the original mass and volume of the settled sample. The densities of the settled solids and supernatant were calculated by dividing the mass of the sample by the measured volume. These measurements were made at 50,70 , and $90^{\circ} \mathrm{C}$. The temperature was controlled by a constant temperature bath or oven.

Before preparation of the composite sample, the shear strengths of the samples from segments 16 , $16 \mathrm{R}$, and 18 were determined. The shear strengths of each of the four diluted and one undiluted composite samples were determined in duplicate at $50^{\circ} \mathrm{C}$. Approximately $30 \mathrm{~mL}$ of each sample was placed in the shear assemblies shown in Figure 2.1. A shear vane (see Figure 2.1) was placed in the sample and held in place with pins; the sample was held at $50^{\circ} \mathrm{C}$ for a minimum of two weeks. The viscometer was attached to the shear vane while it was held in place by the pins. After the viscometer was attached, the pins were pulled from the vane permitting it to rotate. Shear strength was determined by monitoring the torque on the shear vane as it was rotated at a constant velocity. The torque on the vane is proportional to the shear stress of the material. A plot of the shear stress of the material as a function of time at a constant shear rate was obtained for each sample. A typical plot of torque as a function of time is shown in Figure 2.2. The shear strength of the sample $\left(\tau_{\mathrm{g}}\right)$ was calculated from the maximum torque measured by the viscometer $\left(T_{\max }\right)$, (see Figure 2.2$)$ the diameter $\left(D_{v}\right)$, and the height $\left(\mathrm{H}_{v}\right)$ of the shear vane according to the following equation

$$
\tau_{\mathrm{s}}=\frac{\mathrm{T}_{\max }}{\frac{\pi \mathrm{D}_{\mathrm{v}}^{3}}{2}\left(\frac{1}{3}+\frac{\mathrm{H}_{\mathrm{v}}}{\mathrm{D}_{\mathrm{v}}}\right)}
$$

Details of the principle of the rotating shear vane and the derivation of Equation 1 can be found in Nguyen and Boger (1983). For a recent survey of methods to measure the yield stress the reader is referred to Nguyen and Boger (1992). 


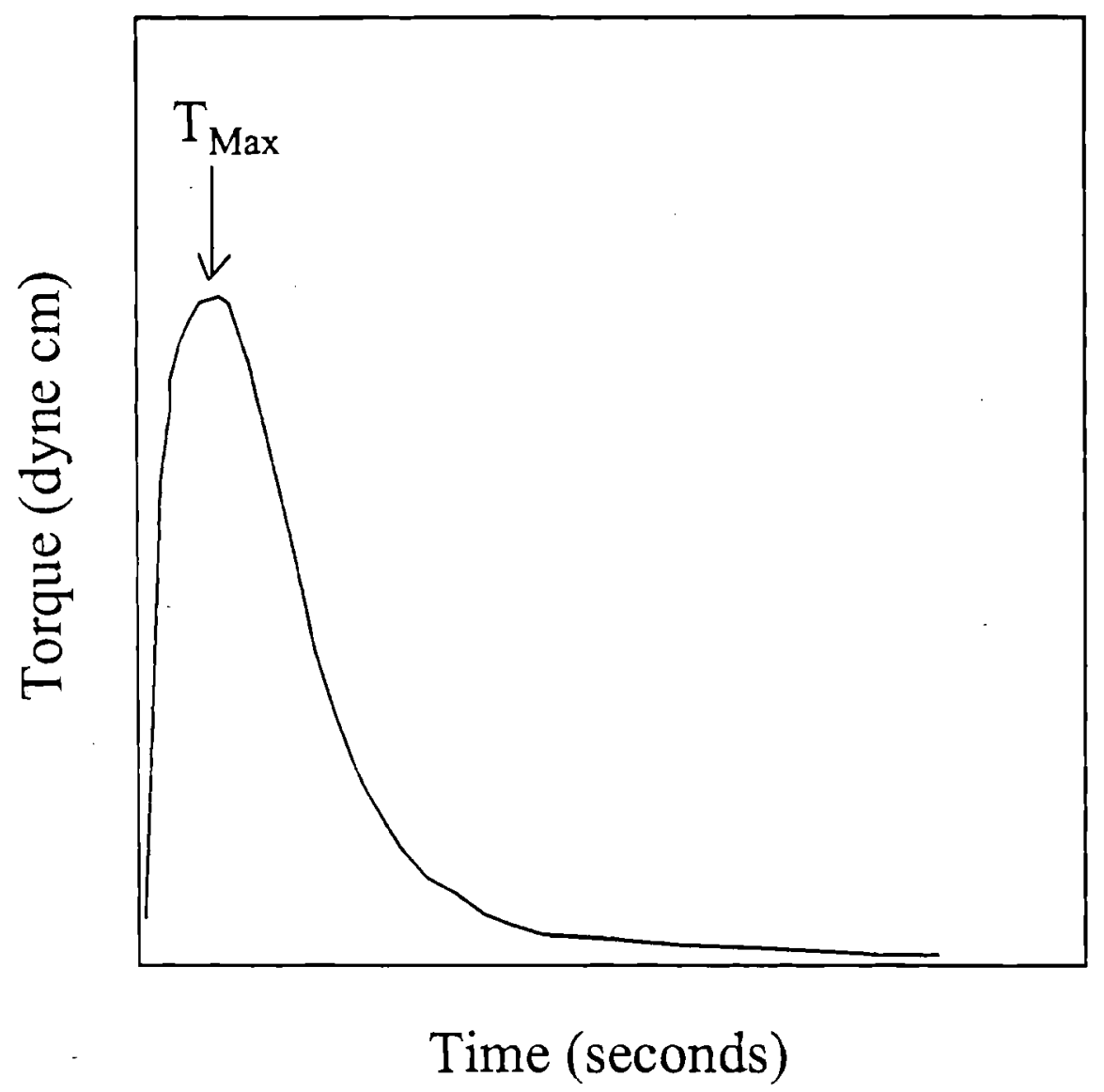

Figure 2.2. Typical Torque Versus Time Curve

The shear strength values at $50^{\circ} \mathrm{C}$ of the dilutions and composite were near or below detection limits $(50 \mathrm{~Pa})$ of the shear vane, and shear strength normally decreases with increasing temperature; therefore, the shear strength was not determined for samples at 70 and $90^{\circ} \mathrm{C}$. The apparent viscosity of each dilution and the composite sample was determined at 50,60 , and $70^{\circ} \mathrm{C}$. Shear stress as a function of shear rate was determined in duplicate on each sample.

Because all samples were pourable, the apparent viscosities of the diluted and undiluted samples were determined in a viscometer with a concentric cylinder geometry. The use of a cone and plate geometry was needed on several previous core samples because the samples were not pourable. A 40-mL subsample of each dilution was placed in the viscometer cup, which was controlled at constant temperature. The samples were equilibrated at the temperature of the measurement for at least one hour prior to being placed in the viscometer cup. Up-curves and down-curves (as defined above) were generated up to a maximum shear rate of $480 \mathrm{~s}^{-1}$. 
Each sample was vacuum filtered through a 0.45 micron nylon filter, and the volume and weight percent of filtered solids were calculated. A vacuum of $28 \mathrm{~cm}$ of mercury was used for filtration. These measurements were made in duplicate at 50,70 , and $90^{\circ} \mathrm{C}$. The samples were equilibrated at these temperatures for a minimum of one hour prior to filtering the sample. During filtration the temperature of the sample was controlled at the desired level.

The density of the filtrate was determined by measuring the volume and mass of the filtrate in a graduated cylinder. The density of the filtered solids was determined by a displacement method. A known mass of filtered solids was placed in a volumetric flask. Normal paraffin hydrocarbon (NPH) of known density was added to the flask to obtain the specified volume of the flask. The mass of NPH added to the flask was measured, and the volume of NPH added to the flask was calculated from the mass of added NPH and the density of the NPH. The volume of the filtered solids was then calculated from the volume of the flask and NPH added. Density was calculated by dividing mass by volume.

No filtrate was obtained from vacuum filtraton of the composite, $10 \% \mathrm{NaOH}$ dilution, and $20 \%$ $\mathrm{NaOH}$ dilution samples; therefore, these samples were filtered using a nine-micron centrifuge filter. The samples were filtered for 15 minutes at $1000 \mathrm{x}$ g-forces to obtain separation of the interstitial liquid and solids. These samples were equilibrated in the same fashion as the vacuum filtered samples, but temperature was not controlled during centrifuging. The centrifuge head was heated to the temperature of the measurement prior to centrifuging the sample. The filtrate and filtered solids densities were determined using the same procedure outlined for the vacuum-filtered samples. 
, 


\subsection{Results}

Effects of heating and dilution on the rheological and physical properties of the composite sample from Tank 241-SY-101 and the four $\mathrm{NaOH}$ diluted samples $(10,20,35$, and 50 volume percent) are presented in this section. The rheological properties presented include shear strength of the segment material before preparation of the composite sample, shear strength of the composite and each dilution at $50^{\circ} \mathrm{C}$, and apparent viscosity of the undiluted and the four diluted samples at 50,70 , and $90^{\circ} \mathrm{C}$. Physical properties, including volume and weight percent settled solids, weight percent filtered solids, settled solids and supernatant densities, filtered solids and filtrate densities, and composite and dilution densities are also discussed in this section.

\subsection{Rheological Properties}

The shear strength of Window C, core sample 22, segments $16,16 \mathrm{R}$, and 18 , as they were received at PNL for the heating and dilution tests, were much lower than what was expected from previous shear strength measurements performed on this core material. ${ }^{(a)}$ The shear strength of the samples as they were received were performed at ambient temperature, which was $30^{\circ} \mathrm{C}$. Shear strengths of segments $16,16 \mathrm{R}$, and 18 are reported in Table 3.1. Previous results were performed on unhomogenized core samples, while segments $16,16 \mathrm{R}$, and 18 samples were homogenized shortly after the samples were extruded. The subsamples shipped to PNL were also homogenized before subsampling for the heating and dilution tests. Previous experience demonstrates that homogenization of waste from Tank 241-SY-101 induces a significant decrease in the shear strength of the sample. This decrease was irreversible over a two-year time period. Other factors that may contribute to the lower observed shear strength include sample aging and inconsistency between samples.

Table 3.1. *Shear Strength of Window C, Core Sample 22, Segment Samples

Shear Strength $(\mathrm{Pa})$

\begin{tabular}{|c|c|c|c|c|}
\hline Segment & Sample & Run 1 & Run 2 & Run 3 \\
\hline 16 & 1 & 220 & 170 & 80 \\
\hline 16 & 2 & 200 & 430 & 330 \\
\hline $16 \mathrm{R}$ & 1 & 260 & 370 & 360 \\
\hline $16 R$ & 2 & 420 & 400 & 190 \\
\hline 18 & 1 & 170 & 190 & 170 \\
\hline 18 & 2 & 440 & 40 & 130 \\
\hline
\end{tabular}

\footnotetext{
*Room temperature
}

(a) Tingey; J. M. February 1992. Physical Characterization of Tank 101-SY Core Samples from Window $C$. Letter report to Westinghouse Hanford Company. Pacific Northwest Laboratory, Richland, Washington.

Tingey, J. M. May 1992. Rheological Properties of Waste from Tank 101-SY. Letter report to Westinghouse Hanford Company. Pacific Northwest Laboratory, Richland, Washington. 
The shear strength of each dilution and the composite sample was determined in duplicate at $50^{\circ} \mathrm{C}$. To minimize sample handling and phase equilibrium effects on the shear strengths of these samples, the temperature of the samples was maintained at $50^{\circ} \mathrm{C}$, and the samples were left undisturbed for a minimum of two weeks before performing these measurements. The shear strengths of the 20,35 , and $50 \% \mathrm{NaOH}$ dilutions at $50^{\circ} \mathrm{C}$ were below the system's detection limits $(50 \mathrm{~Pa})$. The shear strengths of the 0 and $10 \% \mathrm{NaOH}$ dilutions were slightly above the detection limits of the system ( $60 \mathrm{~Pa}$ for the $0 \%$ dilution and $110 \mathrm{~Pa}$ for the $10 \%$ dilution). Because these shear strengths were below or near the system's detection limits and shear strength normally decreases with increasing temperature, the shear strengths of these samples were not determined at 70 or $90^{\circ} \mathrm{C}$.

After performing the shear strength measurements on the four diluted and one undiluted sample, the apparent viscosities and yield points of these same samples were determined. Numerical values for the results of some of these tests are shown in Tables 3.2-3.5. The apparent viscosities of the samples (both the composite and the four dilutions) varied with shear rate at all three temperatures $(50,70$, and $90^{\circ} \mathrm{C}$ ). A yield point was observed in the flow curve of all samples followed by a decreasing slope in the curve with increasing shear rate ( $n$ is less than 1). All samples behaved as time-dependent yield pseudoplastic materials. When there is no time dependence, this behavior is commonly modeled by a yield-power law model, also called the "Herschel-Bulkley" model, (Bird, Dai, and Yarusso 1983). However, for the samples tested herein, a more accurate model would have to include time-dependent parameters. A generalization of the yield-power law model that accounts for time-dependent effects is shown in Equation 2, where $\tau(t)$ is shear stress, $\tau_{0}(t)$ is the yield stress, $\gamma$ is shear rate, $K(t)$ is the consistency factor, and $n(t)$ is the fluid flow index.

$$
\tau(t)=\tau_{0}(t)+K(t) \gamma^{n(t)}
$$

The determination of the functional form of the time-dependent parameters in Equation 2 is beyond the scope of this investigation. Several thixotropic models have been proposed in the literature; however, their use in practical applications has been very limited (Mewis 1979, Berker and VanArsdale 1992). Furthermore, determination of a rheological model suitable to describe the transport of a complex viscoplastic material depends very strongly on the particular process to which the material will be subjected. In contrast to the rheological models for Newtonian fluids or purely viscous nonNewtonian fluids, there are no universal rheological models for time-dependent viscoplastic materials such as the samples investigated in the present work. For a complex fluid, a rheological model must be tailored to the specific geometry with which the material will interact, characteristic range of shear rates, the duration of the process, etc. (Macoscko 1994).

In Figure 3.1 and Table 3.2, the yield point of each sample is plotted as a function of temperature and volume percent $\mathrm{NaOH}$. Only the yield point for the first run was plotted, because these samples exhibit sample history-dependent behavior. The yield points of the 0,10 , and $20 \%$ dilutions decreased significantly after the sample was sheared. Because of the limited sample volume of each dilution, only one sample was available to perform these rheological measurements. In contrast to the more concentrated dilutions, the yield points of the 35 and $50 \%$ dilutions were consistent over multiple runs. 


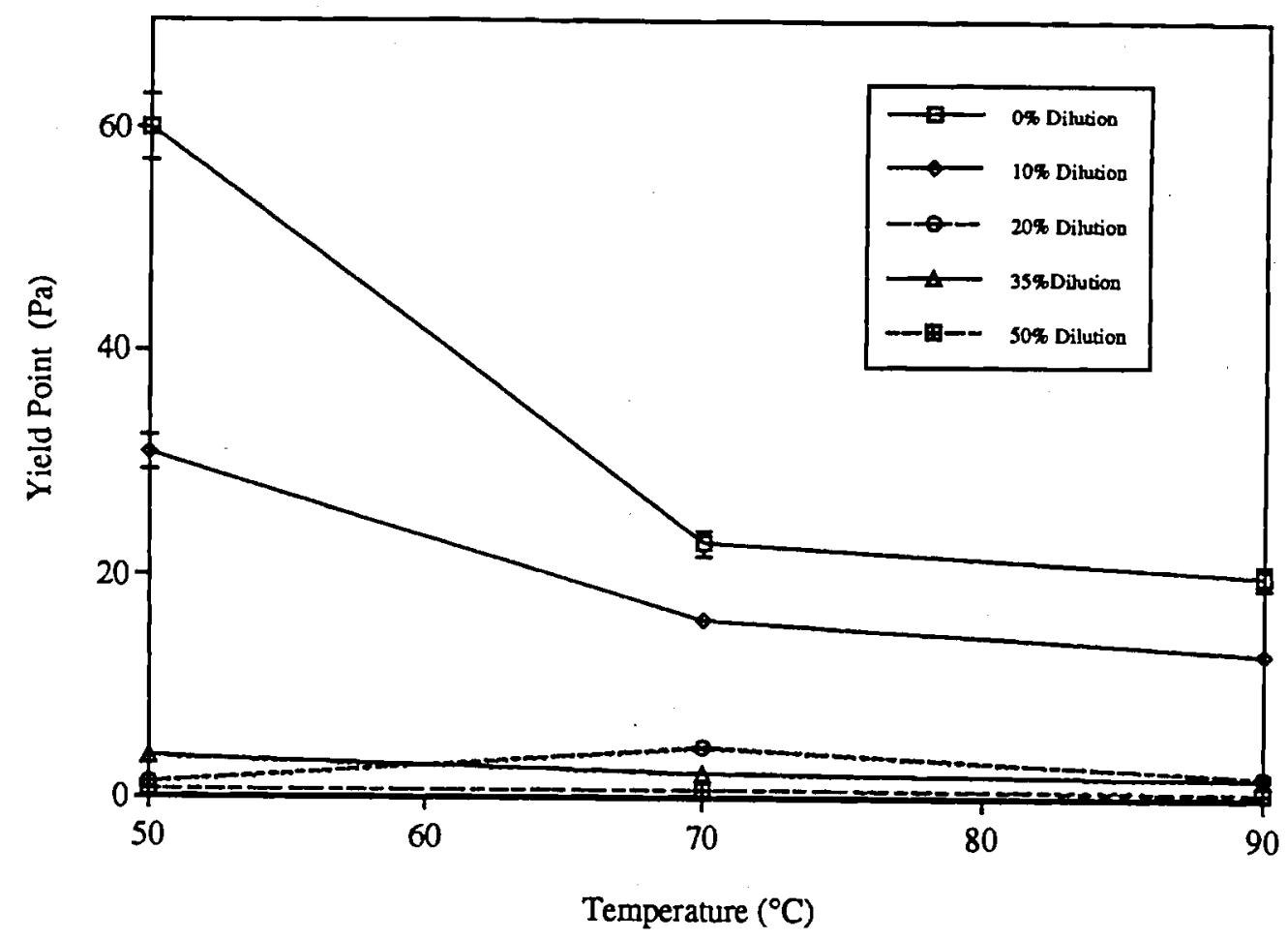

Figure 3.1. Yield Point as a Function of Temperature and Volume Percent $\mathrm{NaOH}$

Yield points of the one undiluted and the four diluted samples decrease with increasing temperature and dilution, as is shown in Figure 3.1. Most of the decrease in the yield point of the sample is observed between 50 and $70^{\circ} \mathrm{C}$ and 0 and $10 \%$ dilutions. The yield point of the $20 \%$ dilution at $50^{\circ} \mathrm{C}$ is suspect, because a larger value was observed in the decreasing shear rate portion of the rheogram than the initial yield point observed when the shear rate was increased.

A decrease in the yield stresses of 241-SY-101 samples after they had been sheared was observed in other core samples from this tank and lower-than-expected shear strengths were obtained for the homogenized segment samples received at PNL. ${ }^{(a)}$ We assume that processes that induce shear forces, such as homogenization and mixing, modify the structural configuration (microstructure) of the material such that the rheological properties of the waste are substantially altered. Previous studies of a Tank 241-SY-101 core sample indicated that a large decrease in the yield stress of the sample is observed shortly after shearing it. Most of this decrease is recovered over a 24-hour time period, but the rheological properties of the sample (yield stress and shear strength) do not return to their original value even after they have been left undisturbed at room temperature for two years.

(a) Tingey, J. M. May 1992. Rheological Properties of Waste from Tank 101-SY. Letter report to Westinghouse Hanford Company. Pacific Northwest Laboratory, Richland, Washington. 
Table 3.2. Yield Point Prior to Shearing

Yield Point $(\mathrm{Pa})$ at Dilution (Volume \% $2 \underline{\mathrm{M}} \mathrm{NaOH})$

\begin{tabular}{|c|c|c|c|c|c|}
\hline Temperature & $0 \%$ & $10 \%$ & $20 \%$ & $35 \%$ & $50 \%$ \\
\hline $50^{\circ} \mathrm{C}$ & 60 & 31 & 1.3 & 3.7 & 0.7 \\
\hline $70^{\circ} \mathrm{C}$ & 23 & 16 & 4.5 & 2.2 & 0.8 \\
\hline $90^{\circ} \mathrm{C}$ & 20 & 13 & 2.0 & 1.8 & 0.6 \\
\hline
\end{tabular}

Apparent viscosities of the composites and dilutions at shear rates above approximately $150 \mathrm{~s}^{-1}$ are essentially constant over multiple runs. The apparent viscosities at a shear rate of $400 \mathrm{~s}^{-1}$ of the one undiluted and four diluted samples are shown as a function of temperature and volume percent $\mathrm{NaOH}$ in Figure 3.2 and Tables $3.3,3.4$, and 3.5 . For the composite and $10 \%$ dilution, the apparent viscosity of the sample decreases significantly with increasing temperature. For the other dilutions $(20,35$, and $50 \%$ ), only small changes in the apparent viscosity were observed as a function of temperature. The apparent viscosities of the samples from Tank 241-SY-101 decrease with increasing dilution. This decrease was observed over the entire range of the dilutions studied.

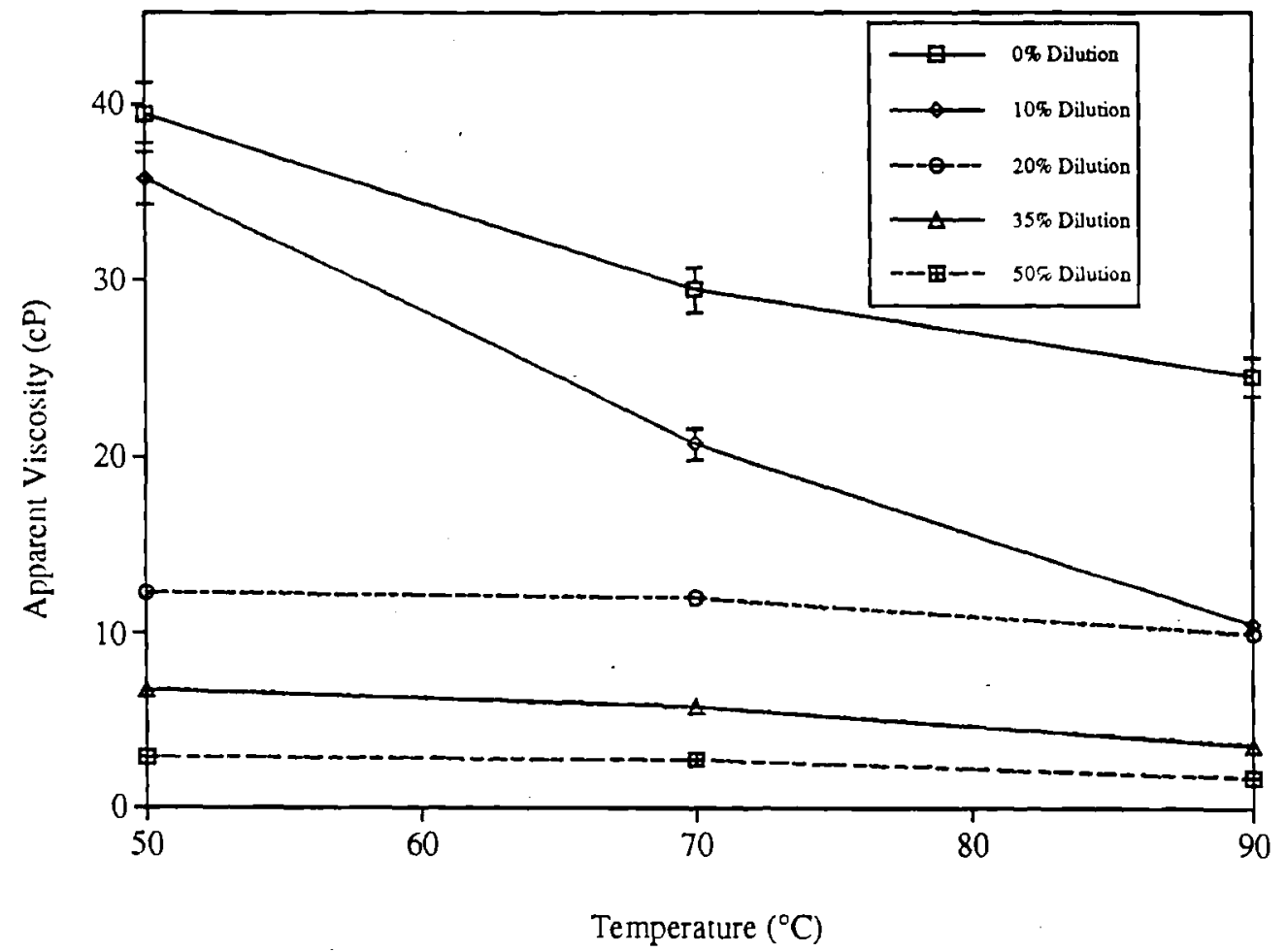

Figure 3.2. Apparent Viscosities at a Shear Rate of $400 \mathrm{~s}^{-1}$ of One Undiluted and Four Diluted Samples as a Function of Temperature and Volume Percent $\mathrm{NaOH}$ 
Table 3.3 Apparent Viscosity at $50^{\circ} \mathrm{C}$ as a Function of Volume Percent $\mathrm{NaOH}$

\begin{tabular}{|c|c|c|c|}
\hline \multicolumn{4}{|c|}{ Apparent Viscosity at $400 \mathrm{~s}^{-1}(\mathrm{cP})$} \\
\hline $\begin{array}{c}\text { Dilution } \\
(\mathrm{Vol} \% 2 \mathrm{M} \mathrm{NaOH}) \\
\end{array}$ & $\# 1$ & $\# 2$ & Ave \\
\hline $0 \%$ & 38.2 & 40.7 & 39.4 \\
\hline $10 \%$ & 36.0 & 35.8 & 35.8 \\
\hline $20 \%$ & 12.3 & 12.3 & 12.3 \\
\hline $35 \%$ & 6.5 & 7.1 & 6.8 \\
\hline $50 \%$ & 2.9 & 2.9 & 2.9 \\
\hline
\end{tabular}

Table 3.4. Apparent Viscosity at $70^{\circ} \mathrm{C}$ as a Function of Volume Percent $\mathrm{NaOH}$

\begin{tabular}{|c|c|c|c|}
\hline \multicolumn{4}{|c|}{ Apparent Viscosity at $400 \mathrm{~s}^{-1}(\mathrm{cP})$} \\
\hline $\begin{array}{c}\text { Dilution } \\
(\mathrm{Vol} \% 2 \mathrm{M} \mathrm{NaOH})\end{array}$ & $\# 1$ & $\# 2$ & Ave \\
\hline $0 \%$ & 28.7 & 30.1 & 29.4 \\
\hline $10 \%$ & 20.7 & - & 20.7 \\
\hline $20 \%$ & 11.6 & 12.4 & 12.0 \\
\hline $35 \%$ & 6.2 & 5.5 & 5.8 \\
\hline $50 \%$ & 2.5 & 3.0 & 2.8 \\
\hline
\end{tabular}

Table 3.5. Apparent Viscosity at $90^{\circ} \mathrm{C}$ as a Function of Volume Percent $\mathrm{NaOH}$

\begin{tabular}{|c|c|c|c|}
\hline \multicolumn{4}{|c|}{ Apparent Viscosity at $400 \mathrm{~s}^{-1}$ (cP) } \\
\hline $\begin{array}{c}\text { Dilution } \\
(\mathrm{Vol} \% 2 \mathrm{M} \mathrm{NaOH})\end{array}$ & $\# 1$ & $\# 2$ & Ave \\
\hline $0 \%$ & 27.4 & 21.6 & 24.5 \\
\hline $10 \%$ & 10.8 & 10.3 & 10.6 \\
\hline $20 \%$ & 9.9 & 10.0 & 10.0 \\
\hline $35 \%$ & 3.5 & 3.7 & 3.6 \\
\hline $50 \%$ & 1.7 & - & 1.7 \\
\hline
\end{tabular}




\subsection{Physical Properties}

Volume percent settled solids of the undiluted and diluted samples at 50,70 , and $90^{\circ} \mathrm{C}$ is reported in Table 3.6. No settling was observed in the undiluted samples at any of the three temperatures. The $10 \%$ dilution exhibited no settling at $50^{\circ} \mathrm{C}$, but a small amount of settling was observed at 70 and $90^{\circ} \mathrm{C}$. A small amount of settling was observed in the $20 \%$ dilution at all three temperatures, but a maximum of only 4 volume percent supernatant was observed in the settled $20 \%$ dilution. The 35 and $50 \%$ dilutions exhibited significant settling at all temperatures. Data for the $35 \%$ dilution at $70^{\circ} \mathrm{C}$ are not reported, because the sample dried during the three day settling period; enough pressure was generated in the centrifuge cone to pop the lids off the centrifuge cones, allowing the sample to dry.

Slurry densities for the one undiluted and the four diluted samples are shown in Table 3.7. Settled solid densities for the one undiluted and the four diluted samples are reported in Table 3.8. Accurate supernatant densities could not be determined for the composite, $10 \%$ dilution, and $20 \%$ dilutions because of the limited amount of supernatant. The supernatant densities of the 35 and $50 \%$ dilutions were 1.26 (0.06 range) and 1.37 (0.02 range) $\mathrm{g} / \mathrm{mL}$, respectively. No significant change in the density of the supernatant was observed as a function of temperature, although some decrease in the density of the settled solids was observed as the temperature was increased. The densities of the settled solids decreased as the percent dilution was increased.

The 35 and $50 \%$ dilutions were vacuum filtered to obtain the density of the filtered solids. The weight percent filtered solids at 50,70 , and $90^{\circ} \mathrm{C}$ are reported in Table 3.9. No separation of supernatant and solids was obtained for the 0,10 , and $20 \%$ dilutions using vacuum filtration; therefore, solid/liquid separation of these samples was obtained by the centrifugation filtration method. The weight percent filtered solids for these samples at 50,70 , and $90^{\circ} \mathrm{C}$ are also reported in Table 3.9. The weight percent filtered solids obtained by the two methods should not be directly compared, because greater forces and a larger pore size were used in the centrifugation method.

Table 3.6. Volume Percent Settled Solids

\begin{tabular}{c}
$\begin{array}{c}\text { Dilution } \\
\text { (Vol\% 2M NaOH) }\end{array}$ \\
\hline $0 \%$ \\
$10 \%$ \\
$20 \%$ \\
$35 \%$ \\
$50 \%$
\end{tabular}

\begin{tabular}{|c|c|}
\hline \multicolumn{2}{|c|}{$50^{\circ} \mathrm{C}$} \\
\hline Vol \% & Range \\
\hline 100 & 0 \\
\hline 100 & 0 \\
\hline 96 & 0 \\
\hline 89 & 1.9 \\
\hline 34 & 0 \\
\hline
\end{tabular}

\begin{tabular}{|c|c|c|c|}
\hline \multicolumn{2}{|c|}{$\begin{array}{c}\text { Temperature } \\
70^{\circ} \mathrm{C} \\
\end{array}$} & \multicolumn{2}{|c|}{$90^{\circ} \mathrm{C}$} \\
\hline Vol \% & Range & Vol\% & Range \\
\hline 100 & 0 & 100 & 0 \\
\hline 98 & 0.3 & 96 & 2.6 \\
\hline 99 & 1.6 & 98 & 4.0 \\
\hline- & - & 76 & 2.5 \\
\hline 34 & 1.8 & 33 & 2.9 \\
\hline
\end{tabular}


Table 3.7. Slurry Density

\begin{tabular}{|c|c|c|c|c|c|c|}
\hline \multirow[b]{2}{*}{$\begin{array}{c}\text { Dilution } \\
\text { (Vol \% } 2 \underline{\mathrm{M}} \mathrm{NaOH})\end{array}$} & & & \multicolumn{2}{|c|}{$\begin{array}{c}\text { Temperature } \\
70^{\circ} \mathrm{C}\end{array}$} & \multicolumn{2}{|c|}{$90^{\circ} \mathrm{C}$} \\
\hline & $\mathrm{g} / \mathrm{mL}$ & Range & $\mathrm{g} / \mathrm{mL}$ & Range & $\mathrm{g} / \mathrm{mL}$ & Range \\
\hline $0 \%$ & 1.72 & 0.01 & 1.61 & 0 & 1.58 & 0.01 \\
\hline $10 \%$ & 1.68 & 0.02 & 1.53 & 0.01 & 1.51 & 0.03 \\
\hline $20 \%$ & 1.60 & 0 & 1.55 & 0.01 & 1.51 & 0.07 \\
\hline $35 \%$ & 1.48 & 0 & 1.42 & 0 & 1.42 & 0.02 \\
\hline $50 \%$ & 1.34 & 0 & 1.29 & 0.01 & 1.25 & 0.03 \\
\hline
\end{tabular}

Table 3.8. Settled Solids Density

\begin{tabular}{|c|c|c|c|c|c|c|}
\hline \multirow[b]{2}{*}{$\begin{array}{c}\text { Dilution } \\
(\mathrm{Vol} \% 2 \underline{\mathrm{M}} \mathrm{NaOH})\end{array}$} & & & \multicolumn{2}{|c|}{$\begin{array}{c}\text { Temperature } \\
70^{\circ} \mathrm{C}\end{array}$} & \multicolumn{2}{|c|}{$90^{\circ} \mathrm{C}$} \\
\hline & $\mathrm{g} / \mathrm{mL}$ & Range & $\mathrm{g} / \mathrm{mL}$ & Range & $\mathrm{g} / \mathrm{mL}$ & Range \\
\hline $0 \%$ & 1.72 & 0 & 1.63 & 0 & 1.58 & 0.02 \\
\hline $10 \%$ & 1.68 & 0.02 & 1.51 & 0.02 & 1.51 & 0.03 \\
\hline $20 \%$ & 1.59 & 0 & 1.57 & 0.02 & 1.51 & 0.07 \\
\hline $35 \%$ & 1.51 & 0.04 & - & - & 1.42 & 0.02 \\
\hline $50 \%$ & 1.42 & 0.03 & 1.38 & 0.04 & 1.25 & 0.03 \\
\hline
\end{tabular}

Table 3.9. Weight Percent Filtered Solids

\begin{tabular}{|c|c|c|c|c|c|c|c|}
\hline \multirow{2}{*}{$\begin{array}{c}\text { Dilution } \\
\text { (Vol\% 2 M } \\
\mathrm{NaOH})\end{array}$} & \multirow[b]{2}{*}{$\begin{array}{l}\text { Filtration } \\
\text { Method }\end{array}$} & \multicolumn{2}{|c|}{$50^{\circ} \mathrm{C}$} & \multicolumn{2}{|c|}{$\begin{array}{c}\text { Temperature } \\
70^{\circ} \mathrm{C}\end{array}$} & \multicolumn{2}{|c|}{$90^{\circ} \mathrm{C}$} \\
\hline & & Wt\% & Range & Wt\% & Range & Wt\% & Range \\
\hline $0 \%$ & Centrifuge & 83 & - & 71 & 2.0 & 66 & 0.9 \\
\hline $10 \%$ & Centrifuge & 60 & - & 61 & 0.8 & 49 & 6.1 \\
\hline $20 \%$ & Centrifuge & 68 & - & 67 & 1.0 & 59 & 4.2 \\
\hline $35 \%$ & Vacuum & 40 & - & 38 & - & 42 & 10.9 \\
\hline $50 \%$ & Vacuum & 25 & 2.3 & 24 & 1.0 & 24 & 5.1 \\
\hline
\end{tabular}


A decrease in the weight percent solids of the composite is evident, as the temperature increases, over the entire range of temperatures. As the amount of solids in the sample increases, the dependence of the weight percent solids on temperature increases.

The densities of the filtrate and filtered solids as a function of temperature and dilution are shown in Figure 3.3 and Tables 3.10 and 3.11. Two molar $\mathrm{NaOH}$ has a density of $1.075 \mathrm{~g} / \mathrm{mL}$ at $30^{\circ} \mathrm{C}$. At 50,70 , and $90^{\circ} \mathrm{C}$, the density of $2 \underline{\mathrm{M} \mathrm{NaOH}}$ decreases to $1.065,1.055$, and $1.042 \mathrm{~g} / \mathrm{mL}$, respectively. The dilutions were prepared at an ambient temperture of $30^{\circ} \mathrm{C}$. The filtrate density of the $50 \%$ dilution correlates well with the settled supernatant values of the same dilution. The filtered solids density is significantly higher than the settled solids density due to the large quantity of interstitial liquid associated with the settled solids.

\subsection{Result Uncertainties}

Error analyses on these results are limited, because most measurements were only performed in duplicate. The error bars in Figures 3.2 and 3.3 indicate the range of values obtained (viscosity and filtrate and filtered solids densities). The error bars in Figure 3.1 are estimated based on instrumental calibration within $10 \%$ of a known viscosity standard because the yield points reported are the first run only due to the thixotropic nature of these samples. The trend lines are used to guide the eye and pass through the average value of each measurement. The data tables include ranges for each value where duplicates were obtained. These tables include shear strength, volume percent settled solids, weight percent filtered solids, and density. Some data were considered invalid based upon significant variances from existing trends or inconsistencies with other related data. 


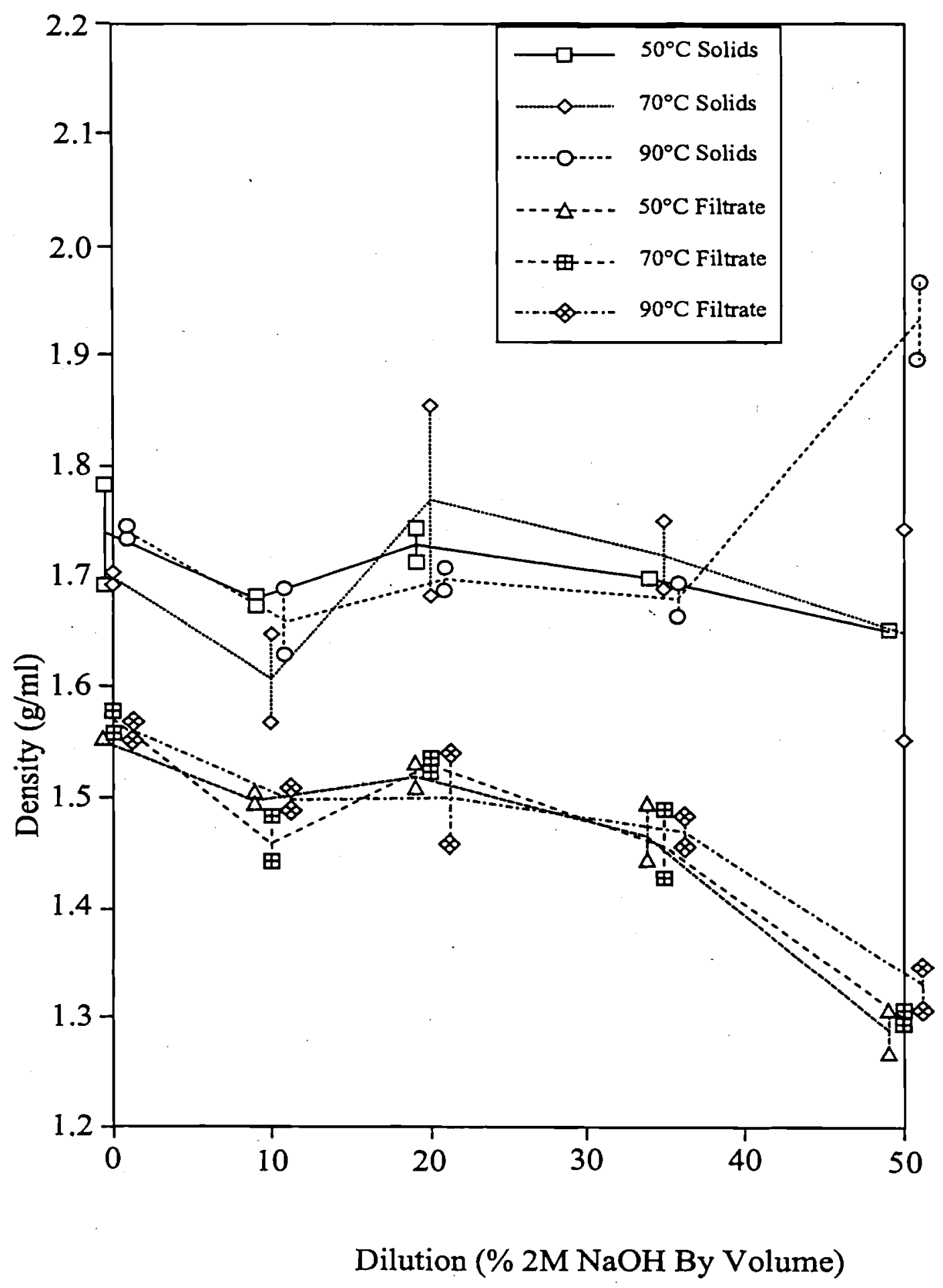

Figure 3.3. Densities of Filtrate and Filtered Solids as a Function of Temperature and Dilution 
Table 3.10. Filtrate Density*

\begin{tabular}{|c|c|c|c|c|c|c|}
\hline \multirow{2}{*}{$\begin{array}{c}\text { Dilution } \\
\text { (Vol\% 2M NaOH) } \\
\end{array}$} & \multicolumn{2}{|c|}{$50^{\circ} \mathrm{C}$} & \multicolumn{2}{|c|}{$\begin{array}{c}\text { Temperature } \\
70^{\circ} \mathrm{C}\end{array}$} & \multicolumn{2}{|c|}{$90^{\circ} \mathrm{C}$} \\
\hline & $\mathrm{g} / \mathrm{mL}$ & Range & $\mathrm{g} / \mathrm{mL}$ & Range & $\mathrm{g} / \mathrm{mL}$ & Range \\
\hline $0 \%$ & 1.55 & - & 1.57 & 0.02 & 1.56 & 0.02 \\
\hline $10 \%$ & 1.50 & 0.01 & 1.46 & 0.03 & 1.50 & 0.02 \\
\hline $20 \%$ & 1.51 & 0.04 & 1.53 & 0.01 & 1.50 & 0.08 \\
\hline $35 \%$ & 1.47 & 0.05 & 1.46 & 0.06 & 1.47 & 0.03 \\
\hline $50 \%$ & 1.29 & 0.04 & 1.30 & 0.01 & 1.33 & 0.03 \\
\hline
\end{tabular}

*Diluent density of $2 \underline{\mathrm{M}} \mathrm{NaOH}=1.075 \mathrm{~g} / \mathrm{mL}$

Table 3.11. Filtered Solids Density

\begin{tabular}{|c|c|c|c|c|c|c|}
\hline \multirow[b]{2}{*}{$\begin{array}{c}\text { Dilution } \\
\text { (Vol \% } 2 \underline{\mathrm{M}} \mathrm{NaOH})\end{array}$} & \multicolumn{2}{|c|}{$50^{\circ} \mathrm{C}$} & \multicolumn{2}{|c|}{$\begin{array}{c}\text { Temperature } \\
70^{\circ} \mathrm{C}\end{array}$} & \multicolumn{2}{|c|}{$90^{\circ} \mathrm{C}$} \\
\hline & $\mathrm{g} / \mathrm{mL}$ & Range & $\mathrm{g} / \mathrm{mL}$ & Range & $\mathrm{g} / \mathrm{mL}$ & Range \\
\hline $0 \%$ & 1.74 & 0.09 & 1.70 & 0.01 & 1.74 & 0.01 \\
\hline $10 \%$ & 1.68 & 0.01 & 1.61 & 0.08 & 1.66 & 0.06 \\
\hline $20 \%$ & 1.73 & 0.03 & 1.86 & 0.17 & 1.70 & 0.02 \\
\hline $35 \%$ & 1.70 & - & 1.72 & 0.06 & 1.68 & 0.03 \\
\hline $50 \%$ & 1.65 & - & 1.65 & 0.19 & 1.93 & 0.07 \\
\hline
\end{tabular}




\subsection{Summary and Conclusions}

In this study, the effects of heating and dilution on the rheological and physical properties of Tank 241-SY-101 waste were investigated. The rheological properties of the waste samples are extremely dependent upon sample shear history. The yield stresses of samples are decreased upon homogenization, mixing, or shearing. This decrease in the yield stress appears to be irreversible, at least in a time span of two years. Because of this dependence upon sample shear history, rheological studies should be performed on undisturbed samples if data on undisturbed in-tank properties are desired.

The composite and all the dilutions exhibited time-dependent yield pseudoplastic behavior. The yield stresses of these samples decrease with increasing temperature and dilution. Most of the decreases in the yield stress were observed between 50 and $70^{\circ} \mathrm{C}$ and 0 and $10 \%$ dilutions.

The apparent viscosities of the composites and dilutions at shear rates higher than $150 \mathrm{~s}^{-1}$ are essentially constant over multiple runs. The apparent viscosities of these samples are dependent upon both temperature and dilution. The temperature dependence of the apparent viscosity is most pronounced in those samples with higher solids content.

Only the 50 and $35 \%$ dilutions exhibited any significant settling and could be vacuum filtered. Solids and liquids in the composite, 10 , and $20 \%$ samples were successfully separated by centrifugation filtering methods. The filtered solids and filtrate densities of all the samples were similar except for the $50 \%$ dilution.

The densities of both the filtrate and solids appear to be independent of temperature. The weight percent filtered solids for the 35 and $50 \%$ dilutions were independent of temperature, but the 10 and $20 \%$ dilutions exhibited a significant decrease in weight percent solids from 70 to $90^{\circ} \mathrm{C}$. The weight percent filtered solids is apparently dependent upon dilution, but only slightly dependent on temperature at the higher dilutions. As the amount of solids in the sample increases, the apparent dependence of the weight percent solids on temperature increases. 


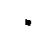




\subsection{References}

Babad, H., G. D. Johnson, J. A. Lechelt, D. A. Reynolds, L. R. Pederson, D. M. Strachan, D. Meisel, C. D. Jonah, and E. C. Ashby. 1991. Evaluation of the Generation and Release of Flammable Gases in Tank 241-SY-101. WHC-EP-0517, Westinghouse Hanford Company, Richland, Washington.

Berker, A., and W. E. VanArsdale. 1992. "Phenomenological Models of Viscoplastic, Thixotropic, and Granular Materials." Rheological Acta, 31:119-138.

Bird, R. B., G. C. Dai, and B. J. Yarusso. 1983. "The Rheology and Flow of Viscoplastic Materials." Reviews in Chemical Engineering, 1:1-70.

Hanlon, B. M. 1994. Tank Farm Surveillance and Waste Status Summary Report for October 1993. WHC-EP-0182-67, Westinghouse Hanford Company, Richland, Washington.

Herting, D. L., D. B. Bechtold, B. A. Crawford, T. L. Welsh, and L. Jensen. 1992a. Laboratory Characterization of Samples Taken in May 1991 from Hanford Waste Tank 241-SY-101.

WHC-SD-WM-TDR-022, Westinghouse Hanford Company, Richland, Washington.

Herting, D. L., D. B. Bechtold, B. A. Crawford, T. L. Welsh, and L. Jensen. 1992b. Laboratory Characterization of Samples Taken in December 1991 (Window E) from Hanford Waste Tank 241-SY-101. WHC-SD-WM-TDR-026, Westinghouse Hanford Company, Richland, Washington.

LANL. 1994. A Safety Assessment for Proposed Pump Mixing Operations to Mitigate Episodic Gas Releases in Tank 241-SY-101: Hanford Site, Richland, Washington. LA-UR-92-3196 Rev 10, Los Alamos National Laboratory, Los Alamos, New Mexico.

Leach, C. E., and S. M. Stahl. 1993. Hanford Site Tank Farm Facilities Interim Safety Basis. WHC-SD-WM-ISB-001 Rev. 0-C, Westinghouse Hanford Company, Richland, Washington.

Macoscko, C. W. 1994. Rheology Principles, Measurements, and Applications. VCH Publishers, Inc., New York.

Mewis, J. 1979. "Thixotropy - A General Review." Journal of Non-Newtonian Fluid Mechanics, $6: 1-20$.

Nguyen, Q. D., and D. V. Boger. 1983. "Yield Stress Measurements in Concentrated Suspensions." Journal of Rheology, 27:321-349.

Nguyen, Q. D., and D. V. Boger. 1992. "Measuring the Flow Properties of Flow Properties of Yield Stress Fluids." Fluid Mechanics, 24:47-88. 
Reynolds, D. A. 1992. Tank 101-SY Window C Core Sample Results and Interpretation. WHC-EP-0589, Westinghouse Hanford Company, Richland, Washington.

Reynolds, D. A. 1993. Tank 101-SY Window E Core Sample: Interpretation of Results.

WHC-EP-0628, Westinghouse Hanford Company, Richland, Washington.

Stewart, C.W., L.A. Schienbein, J.D. Hudson, E.J. Eschbach, and D.L. Lessor, 1994. Assessment of Alternative Mitigation Concepts for Hanford Flammable Gas Tanks. PNL-10105, Pacific Northwest Laboratory, Richland, Washington. 


\section{Distribution}

No. of

Copies

\section{OFFSITE}

12 DOE/Office of Scientific and Technical Information

S. Agnew

Los Alamos National Laboratory MS-C345, Group INC-4

P.O. Box 1663

Los Alamos, NM 87545

K. Pasamehmetoglu

Los Alamos National Laboratory

P.O. Box 1663

MS-K555

Los Alamos, NM 87545

B. C. Hudson

202 Northridge Port

Lindsborg, KS 67456

L. Kovach

NUCON

P.O. Box 29246

Columbus, $\mathrm{OH} 43229$

D. Pepson

U.S. Department of Energy

EM 36/Trevion II

Washington, DC 20585-0002

W. W. Schulz

727 Sweetleaf Drive

Wilmington, DE 19808
No. of

Copies

R. A. Tennant

Los Alamos National Laboratory

Mailstop J565

P.O. Box 1663

Los Alamos, NM 87545

\section{ONSITE}

\section{DOE Richland Operations Office}
R. F. Christensen
S7-54
G. Rosenwald
S7-54
Reading Room
A1-65

16 Westinghouse Hanford Company

H. Babad

S7-30

J. D. Hopkins

R2-11

J. Jewett

T6-09

G. D. Johnson (5)

S7-15

N. W. Kirch

R2-11

J. W. Lentsch

S7-15

N. G. McDuffie

S7-15

D. M. Ogden

$\mathrm{H} 0-34$

M. A. Payne

S7-14

D. A. Reynolds

R2-11

D. J. Sherwood

S7-15

R. J. Van Vleet

H4-63

46 Pacific Northwest Laboratory

G. H. Beeman

S7-71

Z. I. Antoniak

K7-15

R. M. Bean 
No. of

Copies

S. Q. Bennett

P. R. Bredt

K7-90

J. W. Brothers (10)

S. A. Bryan

G. H. Bryan

J. A. Campbell

J. B. Colson

B. K. Eaton

P. C. Hays

J. D. Hudson

P. A. Gauglitz

S. C. Goheen

P7-41

P8-08
No. of

\section{Copies}

B. M. Johnson, Jr.

K1-78

L. R. Pederson

L. A. Schienbein

K2-44

K5-20

K2-10

L. J. Sealock

E. H. Shade

C. W. Stewart

D. M. Strachan

J. M. Tingey (10)

D. S. Trent

Publishing Coordination

Technical Report Files (5)
P7-25

K7-15

K2-44

P7-25

K7-15

K1-06 